\title{
Pre-vaccine era cervical human papillomavirus infection among screening population of women in west Austria
}

Wegene Borena ${ }^{1 *}$, Margarethe Grünberger ${ }^{1}$, Andreas Widschwendter ${ }^{2}$, Karl Heinz Kraxner ${ }^{3}$, Elisabeth Marth ${ }^{4}$, Peter Mayr ${ }^{5}$, Joerg Meier ${ }^{6}$, Norman Ruth', Aida Tort Guerrero ${ }^{1}$, Christian Marth² and Dorothee Holm-von Laer ${ }^{1}$

\begin{abstract}
Background: In order to evaluate the newly implemented gender-neutral HPV vaccination program, knowledge on the pre-vaccine prevalence of HPV infection is of paramount importance. Data on HPV infection among the women with no known previous cytological abnormalities are inexistent in Austria. This study presents data on the prevalence and distribution of HPV genotypes among women with no known cytological abnormalities in west Austria.

Methods: Women between 18 and 65 years of age attending annual cervical cancer screening examinations were included in the study. Data on socio-demographic and reproductive factors were collected using structured questionnaires. Corresponding cervical swab samples were tested for the presence of HPV DNA and were genotyped. Questionnaire data and HPV status were linked with the corresponding cytological findings.

Results: A total of 542 women were included in the study. The mean age of the study participants was 35.9 (SD =11. 5). The prevalence of HPV infection was $20.5 \%$. HPV 16 (6.5\%), HPV 33 (3.3\%) and HPV 31 (3.0\%) were the dominant genotypes detected. Multivariate analysis showed that women younger than 30 years of age, smokers, women with a higher number of lifetime sexual partners and those living in the eastern districts of the study region were at significantly higher risk of HPV infection.

Conclusions: With this study we present the first data on the prevalence of cervical HPV genotypes among a screening population in Austria. The results not only fill the missing information on HPV infection in this group of women in the country, they also provide baseline data for a future evaluation of the impact of the Austrian gender-neutral HPV immunization program. Moreover, our finding of higher HPV prevalence in the eastern compared to the western district of the study region may - at least partly - explain the east-west gradient in the standardized incidence rate of cervical cancer in the region.
\end{abstract}

Keywords: HPV epidemiology, Womens' health, Cervical cancer, HPV vaccine

Abbreviations: AIS, Adenocarcinoma in situ; ASCUS, Atypical squamous cells of undetermined significance; BMI, Body mass index; Cl, Confidence interval; DNA, Dioxyribonucleic acid; dUTP/UNG, Uridine-5'-triphosphate/ uracil-N-glycosylase; HPV, Human papillomavirus; HrHPV, High risk human papillomavirus; HSIL, High grade suqamous epithelial lesion; IARC, International agency for research on cancer; IBK, Innsbruck; ICO, Institut Catalana D’Oncologia; IL, Innsbruckland; LSIL, Low grade squamous epithelial lesion; OR, Odds ratio; PCR, Polymerase chain reaction; SD, Standard deviation; SIR, Standardized incidence rate; WHO, World Health Organization

\footnotetext{
* Correspondence: wegene.borena@i-med.ac.at

'Division of Virology, Medical University of Innsbruck, Schoepfstrasse 41, 6020

Innsbruck, Austria

Full list of author information is available at the end of the article
} 


\section{Background}

Genital human papillomavirus (HPV) infection is the most common sexually transmitted viral infection [1]. It is mostly transient resulting in no cervical lesions or leading to low-grade lesions that often regress spontaneously. However, a non-negligible proportion of the infections persists and results in subsequent pre-cancerous and cancerous lesions [2, 3].

For the prevention of cervical and other genital neoplasia, three vaccines - Gardasil $^{\bullet}$ (quadrivalent vaccine against HPV types 6, 11, 16 and 18), Gardasil $9^{\circ}$ (nonavalent vaccine against HPV types 6, 11, 16, 18, 31, 33, 45, 52 and 58) and Cervarix ${ }^{\odot}$ (bivalent vaccine against HPV types 16 and 18) - have been approved for use [4-7]. Developed nations like Australia and several countries in Europe and North America have integrated HPV immunisation in their vaccination programs soon after the approval. Accordingly, in these countries significant reductions have been observed in many high-risk HPV (hrHPV) infections as well as in HPV-associated warts and precancerous lesion [8-10].

In Austria these vaccines have been recommended and available for use since their approval $[11,12]$. However, it is only since the beginning of 2014 that the country integrated HPV vaccine in the free of charge immunization program [12]. Starting from the autumn of 2014, 4th grade elementary school girls and boys receive two doses of Gardasil (0-6 months) as part of school-based immunization program. In order to assess the longterm impact of this program, pre-vaccine data on the prevalence of HPV infection and genotype distribution are of paramount importance [11].

Data on the prevalence of HPV infection is scarce in Austria. Until the end of 2013 the only data available were those on HPV prevalence in cervical cancer samples $[13,14]$. L Rössler et al. recently published data on the prevalence of HPV among Austrian women with high- grade intraepithelial lesions [15]. However, to date, there are no data on the epidemiology of HPV infection among women without any known cytological abnormalities (Additional file 1: Figure S1). One of the early parameters in evaluating the success of HPV immunisation programs is the comparison of HPV prevalence in the pre- and post-HPV-vaccine era.

The main aim of this study is to present data on the distribution of HPV genotypes among screening population of women in west Austria. With this study, we also aim to address the role of HPV infection in an interesting difference in the cervical cancer incidence observed between eastern (standardized incidence rate (SIR) in the range of 1.2 to 1.5 ) and western (SIR in the range of 0.6 to 0.9 ) districts of the study region [16]. To our knowledge this is the first report on the epidemiology of cervical HPV infection among screening population of women in Austria.

\section{Methods}

\section{Study population}

The study population included sexually active women aged 18-65 years undergoing routine gynaecological screening at five randomly selected gynaecological clinics in west Austria (Tyrol) between March 2013 and February 2015. Screening for cervical cancer in Austria is opportunistic in nature but is provided free-of-charge at a yearly basis. Women who have consented to participate in the study filled out questionnaires on socio-demographic, reproductive and sexual characteristics. The questionnaires were then sent back to our institute (Division of Virology of the Medical University of Innsbruck) with the corresponding cervical samples.

For the ascertainment of persistent HPV infection, those women who tested positive for one or more of the known hrHPV types were invited for a follow up HPV testing approximately a year after the baseline.

\section{The samples}

One of the two swabs taken from the patient was sent to our institute, the other one was sent to a pathology laboratory (Dr. P. O.) for cytological (PAP) examination. Cervical swabs were taken with Abbott Cervi-Collect specimen collection kit. DNA extraction (Biomerieux EasyMag 2.0) took place within 2 days of arrival of samples at our institute. The extracted DNA samples were stored at $-20{ }^{\circ} \mathrm{C}$ until HPV testing.

\section{Detection and Genotyping of HPV}

For the detection and genotyping of HPV, we used a twostep testing procedure. The first test is a real-time PCR that identifies the presence or absence of HPV DNA (HPV RealQuality, AB Analitica, Padova, Italy). The second step involves genotyping of all positive samples using a reverse line blot hybridization system (AmpliQuality HPV-TYPE EXPRESS, AB Analitica, Padova, Italy). This genotyping kit was able to identify 40 different HPV types, including all high-risk, probable high-risk and low-risk types. Membrane stripes coated with genotype specific DNA probes are used to identify the different genotypes through hybridization of denatured PCR product. Multiple infections were easily detected. The analysis includes dUTP/UNG system for the prevention of contamination due to carry-over.

\section{Cytology}

Cytological examinations were interpreted according to Munich Nomenclature for the Cytological Diagnosis of Cervical Pap smears [17]. In our study cytological findings were classified as abnormal (PAP III+) if the pathologist reported PAP III (unclear finding corresponding in the Bethesda classification system to ASCUS), PAP IIID (cells of mild or moderate dysplasia corresponding 
in the Bethesda classification system to LSIL or HSIL respectively), PAP IVA (cells of severe dysplasia or carcinoma in situ corresponding in the Bethesda classification system to HSIL or AIS, respectively), PAP IVB (cells of invasive carcinoma not safely excluded, corresponding in the Bethesda classification system to HSIL or AIS with features suspicious for invasion, respectively) or PAP V (cells of invasive cervical carcinoma).

\section{Data analysis}

HPV prevalence was computed in crude and age standardized manner. Chi square or Fischer's exact test (two-tailed) were used for analysis of distribution of several hrHPV genotypes. Logistic regression model was used to compute odds ratios for HPV positivity across several variables including smoking status, educational level, marital status, number of life time sexual partners and age at first sexual contact with corresponding $95 \%$ confidence intervals. $P$-values $<0.05$ were considered significant. Prevalence ratio of HPV infection was also computed across Tyrolean districts.

Statistical analyses were performed in SPSS (Version 20.0. Armonk, NY: IBM Corp.).

\section{Results}

Baseline characteristics

Baseline characteristics of the study participants are presented in Table 1. A total of 542 women were included in this study. The mean age of the study participants was $35.9(\mathrm{SD}=11.5)$ years. One third of the women were current smokers and $27 \%$ were overweight. Mean age at first sexual contact was 16.8 years $(\mathrm{SD}=2.2)$. A quarter of the study participants reported to have had more than five life-time sexual partners. Two hundred thirteen (39.3 \%) participants in this study were from eastern Tyrolean districts (Kufstein, Kitzbühel) whereas 205 (37.8 \%) represent two western districts (Imst and Landeck). Just over a fifth of the participants were from the city of Innsbruck (IBK) or its suburbs (IL). Additional file 2: Figure S2 presents a map of the studied region.

\section{HPV immunization}

Immunisation coverage among the studied population was very low $(3.7 \%)$. The attitude of the study participants towards HPV vaccine is presented in Table 1. Not knowing about the vaccine and/or not being informed about it was the most frequent reason given by the study participants for not being vaccinated. When asked if they would get vaccinated provided the vaccine was available for free, the majority of the study participants showed undecidedness and a minority (13\%) declined clearly.
Table 1 Baseline characteristics of study participants

\begin{tabular}{|c|c|}
\hline & Total $(n=542)$ \\
\hline \multicolumn{2}{|l|}{ Age, years } \\
\hline Mean (SD) & $35.9(11.5)$ \\
\hline Median & 34.5 \\
\hline \multicolumn{2}{|l|}{ Participants per district, $n$ (\%) } \\
\hline Oberland & $205(37.8)$ \\
\hline Unterland & $213(39.3)$ \\
\hline IBK & $68(12.5)$ \\
\hline $\mathrm{IL}$ and others & $55(10.1)$ \\
\hline \multicolumn{2}{|l|}{$\mathrm{BMl}, \mathrm{kg} / \mathrm{m} 2$} \\
\hline Mean (SD) & $23.4(4.0)$ \\
\hline \multicolumn{2}{|l|}{ Smoking status, $n$ (\%) } \\
\hline Current smoker & $175(32.3)$ \\
\hline Non-smokers & $364(67.1)$ \\
\hline \multicolumn{2}{|c|}{ Life time sexual Partners, $n$ (\%) } \\
\hline$\leq 5$ & $340(62.7)$ \\
\hline $6-10$ & $95(17.5)$ \\
\hline$\geq 11$ & $41(7.6)$ \\
\hline \multicolumn{2}{|l|}{ HPV vaccinated, $n$ (\%) } \\
\hline At least one vaccine & $20(3.7)$ \\
\hline \multicolumn{2}{|c|}{ Reasons for not being vaccinated, $n(\%)$} \\
\hline Did not know & $201(37.1)$ \\
\hline Expensive & $42(7.8)$ \\
\hline Fear of side effect & $78(14.4)$ \\
\hline Other reasons & $155(28.6)$ \\
\hline No response & $86(15.9)$ \\
\hline \multicolumn{2}{|c|}{ If vaccine available for free, $n$ (\%) } \\
\hline Will get vaccinated & $179(33)$ \\
\hline Will not get vaccinated & $72(13.3)$ \\
\hline Do not know & $233(43)$ \\
\hline No response & $58(10.7)$ \\
\hline
\end{tabular}

$S D$ standard deviation, $B M I$ body mass index

Oberland western districts (Imst, Landeck)

Unterland Eastern districts (Kufstein, Kitzbuehel), IBK Innsbruck, IL suburbs of Innsbruck

\section{HPV prevalence}

Figure 1 shows the distribution of all detected genotypes among HPV positive women. A total of 111 (20.5\%) participants were positive for one or more of HPV genotypes. Among the high risk types HPV 16 is the most commonly detected genotype followed by HPV 33 and HPV 31. Out of the low risk genotypes HPV 53 and HPV 54 are the most commonly detected types followed by HPVs 82 and 90 . Only three participants $(2.7 \%$ of HPV positive participants) were positive for HPV 6 and none had HPV 11. 


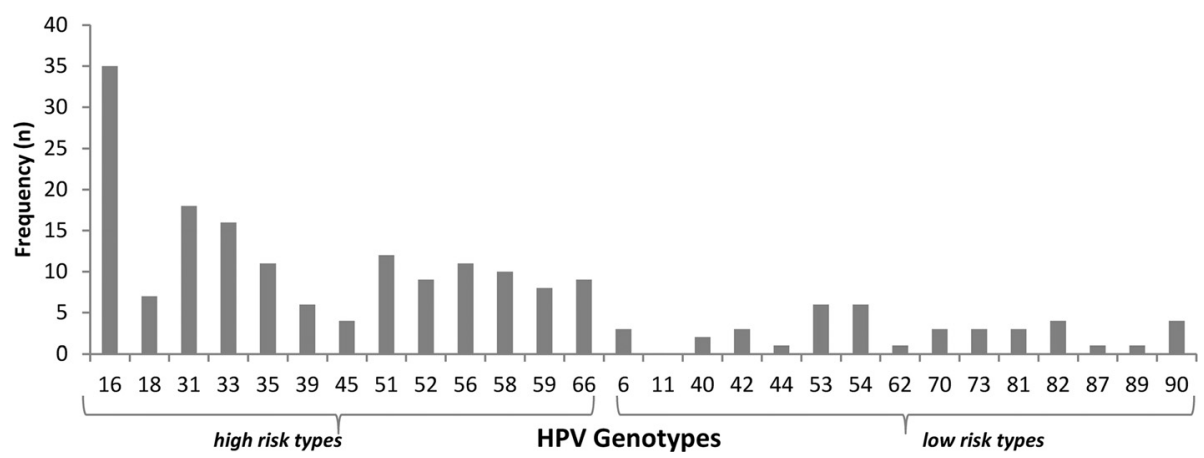

Fig. 1 Distribution (\%) of all detected HPV genotypes among screening population of women in west Austria

Fifty women (45.5\%) had HPV infection with multiple genotypes whereas the slight majority presented with single-genotype infections (Additional file 3: Figure S3). The majority of the participants $(91.8 \%)$ are positive for one of the genotypes classified as definitive, probable or possible carcinogenic HPV types (IARC classification) (Additional file 4: Figure S4) whereas only nine of HPV positive participants $(8.2 \%)$ had infections with only low risk genotypes [18]. A total of 73 women (65.7\% of HPV positive women) are positive for one or more of the high-risk genotypes that are covered in the nonavalent HPV vaccine (HPV-types 16, 18, 31, 33, 45, 52 and 58).

Table 2 characterises the prevalence of any HPV and selected high-risk types by socio-domographic and behavioural data. HPV infection was significantly higher among individuals younger than 30 years of age. Smoking, being single and/or divorced, having several lifetime sexual partners and starting sexual contact at a younger age were significantly associated with higher cervical HPV DNA detection rate. On the contrary higher body mass index (BMI) was not associated with increased risk of HPV infection showing rather a protective effect with a borderline statistical significance. Analysis across Tyrolean districts showed that HPV prevalence was higher among women from the eastern districts compared to those from the west. The significant association disappeared when analysis was adjusted for age, indicating that the observed difference may be due to differences in the age distribution of the study participants in these two regions. A further analysis was done among women above the age of 30 years $(n=342)$ as the clinical and diagnostic relevance of HPV infection is higher in women beyond the age of 30 (Table 3). In this sub-population we found no significant difference in the age distribution across the districts $(P=0.53)$. Multivariable analysis of HPV prevalence in this age group showed still significantly higher HPV prevalence in the eastern compared to the western districts.
The peak age of overall HPV infection, multiple infections and infection with the commonest genotypes lies between 21 and 25 years. This is followed by two lower peaks at 36 to 40 years and at 50 to 55 years. Figure 2 shows the trends in HPV prevalence across age groups. The overall trends in HPV prevalence peaks were

Table 2 Prevalence of HPV Infection by demographic and behavioural characteristics among non-vaccinated women $(n=522)^{a}$

\begin{tabular}{|c|c|c|c|}
\hline Variables & $\begin{array}{l}\text { Variable } \\
\text { categories }\end{array}$ & $\begin{array}{l}\text { Any HPV type } \\
(n=111) \\
\text { OR }(95 \% \text { Cl) }\end{array}$ & $\begin{array}{l}\mathrm{HrHPV}^{\mathrm{b}} \\
(n=73) \\
\mathrm{OR}(95 \% \mathrm{Cl})\end{array}$ \\
\hline \multirow[t]{2}{*}{ Age } & $<30$ years & 1 & 1 \\
\hline & $\geq 30$ years & $0.38(0.25-0.60)^{*}$ & $0.34(0.21-0.57)^{*}$ \\
\hline \multirow[t]{2}{*}{ Marital status } & $\begin{array}{l}\text { Married/ } \\
\text { Partnershaft }\end{array}$ & 1 & 1 \\
\hline & Single/divorced & $1.87(1.17-2.99)^{*}$, & $1.16(0.66-2.10)$ \\
\hline \multirow{2}{*}{$\begin{array}{l}\text { Educational } \\
\text { status }\end{array}$} & Basic schooling & 1 & 1 \\
\hline & $\begin{array}{l}\text { High school and } \\
\text { more }\end{array}$ & $0.81(0.53-1.25)$ & $0.83(0.50-1.37)$ \\
\hline \multirow[t]{2}{*}{ Districts } & Oberland $^{c}$ & 1 & 1 \\
\hline & Unterland $^{d}$ & $1.76(1.06-2.92)^{*}$ & $1.57(0.88-2.79)$ \\
\hline \multirow[t]{2}{*}{ Smoking } & non-smoker & 1 & 1 \\
\hline & smoker & $4.10(2.6-6.41)^{*}$ & $3.16(1.89-5.26)^{*}$ \\
\hline \multirow[t]{2}{*}{ BMI } & $<25$ & 1 & 1 \\
\hline & $\geq 25$ & $0.55(0.32-0.95)^{*}$ & $0.64(0.34-1.19)$ \\
\hline \multirow{2}{*}{$\begin{array}{l}\text { Age at first } \\
\text { sexual contact }\end{array}$} & $<16$ years & 1 & 1 \\
\hline & $\geq 16$ years & $0.44(0.27-0.72)^{*}$ & $0.61(0.35-1.08)$ \\
\hline \multirow[t]{2}{*}{ LSP } & $<6$ & 1 & 1 \\
\hline & $\geq 6$ & $2.40(1.39-3.62)^{*}$ & $1.95(1.13-3.36)^{*}$ \\
\hline
\end{tabular}

$B M I$ body mass index, LSP number of life time sexual partners, OR odds ratio, $\mathrm{Cl}$ confidence interval

${ }^{*} p$-value $=$ statistically significant anly non-vaccinated women

${ }^{b} H P V s$ 16, 18, 31, 33, 45, 5258 (all the HrHPV types included in nonavalen HPV vaccine) 'western districts (Imst, Landeck)

dEastern districts (Kufstein, Kitzbuehel)

esignificant for study participants above 30 years of age 
Table 3 Multivariable adjusted prevalence of HPV Infection by demographic and behavioural characteristics among women above and below 30 years of age ${ }^{a}$

\begin{tabular}{|c|c|c|c|c|c|}
\hline \multirow{4}{*}{ Variables } & \multirow{4}{*}{ Variable categories } & \multicolumn{2}{|c|}{ Women $\geq 30$ years } & \multicolumn{2}{|c|}{ Women $<30$ years } \\
\hline & & Any HPV type & $\mathrm{HrHPV}^{\mathrm{b}}$ & Any HPV type & $\mathrm{HrHPV}^{\mathrm{b}}$ \\
\hline & & $(n=49)$ & $(n=31)$ & $(n=55)$ & $(n=41)$ \\
\hline & & OR $(95 \% \mathrm{Cl})$ & OR $(95 \%$ Cl) & OR $(95 \% C l)^{a}$ & OR (95 \% Cl) \\
\hline \multirow[t]{2}{*}{ Marital status } & Married/Partnershaft & 1 & 1 & 1 & 1 \\
\hline & Single/divorced & $1.89(0.87-4.14)$ & $1.28(0.49-3.32)$ & $1.29(0.58-2.85)$ & $0.82(0.35-1.93)$ \\
\hline \multirow[t]{2}{*}{ Educational status } & Basic schooling & 1 & 1 & 1 & 1 \\
\hline & High school and more & $0.96(0.47-1.97)$ & $1.60(0.67-3.82)$ & $0.52(0.24-1.17)$ & $0.39(0.17-0.94)^{*}$ \\
\hline \multirow[t]{2}{*}{ Districts } & Oberland $^{c}$ & 1 & 1 & 1 & 1 \\
\hline & Unterland $^{\mathrm{d}}$ & $2.43(1.06-5.60)^{*}$ & $2.66(0.98-7.24)^{\mathrm{e}}$ & $0.79(0.32-1.96)$ & $0.98(0.38-2.50)$ \\
\hline \multirow[t]{2}{*}{ Smoking } & non-smoker & 1 & 1 & 1 & 1 \\
\hline & smoker & $2.64(1.30-5.37)^{*}$ & $2.09(0.90-4.84)$ & $3.34(1.53-7.29)^{*}$ & $3.07(1.33-7.09)^{*}$ \\
\hline \multirow[t]{2}{*}{ BMl } & $<25$ & 1 & 1 & 1 & 1 \\
\hline & $\geq 25$ & $0.39(0.16-0.96)^{*}$ & $0.38(0.13-1.17)$ & $1.30(0.51-3.30)$ & $1.98(0.84-4.67)$ \\
\hline \multirow[t]{2}{*}{ Age at first sexual contact } & $<16$ years & 1 & 1 & 1 & 1 \\
\hline & $\geq 16$ years & $1.06(0.37-3.00)$ & $2.43(0.51-11.5)$ & $0.88(0.40-1.94)$ & $1.18(0.50-2.77)$ \\
\hline \multirow[t]{2}{*}{ LSP } & $<6$ & 1 & 1 & 1 & 1 \\
\hline & $\geq 6$ & $2.23(1.06-4.68)^{*}$ & $2.11(0.88-5.06)$ & $0.86(0.39-1.88)$ & $0.98(0.43-2.71)$ \\
\hline
\end{tabular}

$B M I$ body mass index, LSP number of life time sexual partners

$O R$ odds ratio, $C l$ confidence interval, $L S P$ lifetime sexual partner

${ }^{*} p$-value $=$ statistically significant

analysis using only non-vaccinated women, analysis adjusted for age, age at first sexual contact, LSP and smoking

${ }^{b}$ HPVs 16, 18, 31, 33, 45, 5258 (all the HrHPV types included in nonavalen HPV vaccine)

'western districts (Imst, Landeck)

${ }^{d}$ Eastern districts (Kufstein, Kitzbuehel)

eborderline significant

statistically significant for overall HPV positivity $(P=0.001)$ and for common high risk type infections $(P=0.035)$.

The compliance for HPV re-testing a year after the initial test was low. A total of only 48 (47.1\%) women initially positive for any hrHPV genotype were re- tested 1 year after the baseline examination. Twenty five $(52.1 \%)$ of the infections were persistent. No statistically significant association was observed between HPV persistence and any of the sociodemographic factors.

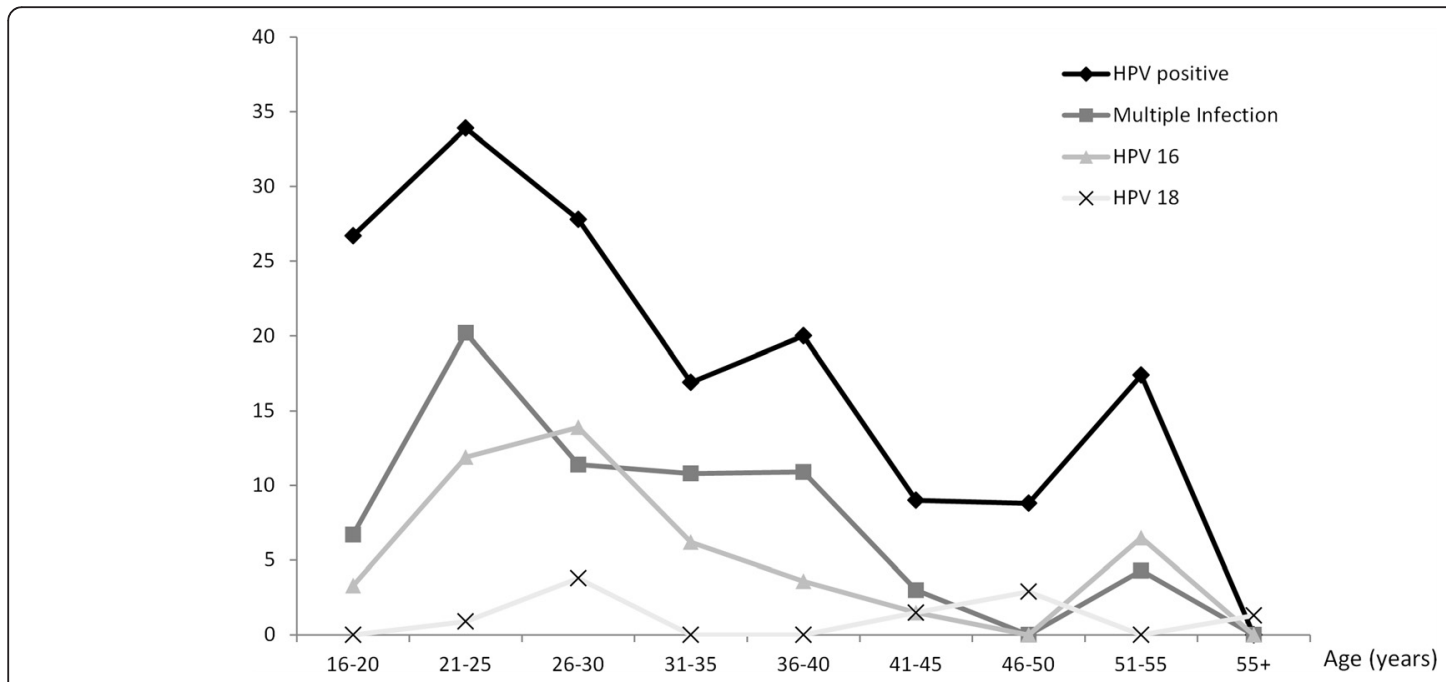

Fig. 2 Trends in age specific HPV prevalence among screening population of women in west Austria 


\section{Cytology}

Data on cytological examination were available for a total of 384 women (Table 4). Twenty one (3.7\%) women were diagnosed with PAPIII+, which were significantly associated with overall, high risk type and multiple HPV infection $(\mathrm{P}<0.0001)$. Of the high-risk types, HPV 16 and 18 were significantly associated with adverse cytological outcomes. Twenty four percent of HPV 16 positive women have accompanying cytological findings of PAP III+. The proportion of smokers is significantly higher among those with PAP III+ [OR $=4.15$ (95 \% CI: 1.63-10.57)]. A total of 48 high-risk positive patients were re-tested once again 9-15 months after the baseline examination. Twenty-three $(52 \%)$ women had persistent infection, the majority of them being HPV 16. Persistent HPV infection was higher among those with abnormal PAP finding, however not statistically significant $[\mathrm{OR}=1.56$ (95 \% CI: 0.41-5.84)].

\section{Discussion \\ HPV prevalence}

Prevalence of HPV DNA in a screening population of women aged 18 to 65 years in west Austria was $20.5 \%$, with the highest prevalence (33.9 \%) seen among women aged 21 to 25 years. Although the overall prevalence was slightly higher than the crude HPV prevalence worldwide, the pattern of age specific HPV prevalence was shown to correspond to that seen in other regions [19-21]. Slight differences may be due to

Table 4 HPV prevalence and distribution of high risk and low risk genotypes across cytological findings

\begin{tabular}{lll}
\hline & $\begin{array}{l}\text { PAP positive } \\
(\text { PAP III+) }(n=21)\end{array}$ & $\begin{array}{l}\text { PAP negative } \\
(\text { PAP I-II) }(n=363)\end{array}$ \\
\hline Age, years & $32.6(8.1)$ & $35.9(11.5)$ \\
Mean (SD) & & $16.8(2.4)$ \\
Age at firts sexual contact, years & $16.8(2.8)$ & \\
Mean (SD) & & $23.4(4.0)$ \\
BMl, Mean (SD) & $22.5(3.3)$ & $117(32.5)^{*}$ \\
Current smoker, $n(\%)$ & $14(66.7)$ & $75(20.7)^{*}$ \\
HPV positive, $n$ (\%) & $19(90.5)$ & $33(9.1)^{*}$ \\
Multiple HPV infection, $n(\%)$ & $7(33.3)$ & $48(13.2)^{*}$ \\
Nonavalent type HrHPV, $n(\%)^{a}$ & $15(71.4)$ & $20(5.8)^{*}$ \\
HPV 16, $n$ (\%) & $9(45)$ & $4(1.1)^{*}$ \\
HPV 18, $n$ (\%) & $2(9.5)$ & $13(3.6)$ \\
HPV 31, $n$ (\%) & $1(4.8)$ & $14(3.9)$ \\
HPV 33, $n$ (\%) & $1(4.8)$ &
\end{tabular}

$S D$ standard deviation, $\mathrm{HrHPV}$ high risk HPV genotypes

PAP III + abnormal PAPanicolaou (cervical smear cytology) including PAP III, PAP IIID, PAP IVA and IVB and PAP V

PAPI-II normal PAPanicolaou (cervical smear cytology)

${ }^{*} P=$ sig

${ }^{\mathrm{a}} 16,18,31,33,45,5258$ (all HrHPV types included in nonavalen HPV vaccine) differences in the type of test used for the HPV detection or differences in the study population selected. Slightly over $60 \%$ of all the infections are detected among women below 25 years of age, which may represent a high susceptibility of HPV infection right after sexual debut. Like in studies from other region, our study also showed other smaller peaks in higher age groups [22]. There is no clear reason as to why HPV prevalence peaks once again in a later age. One commonly accepted assumption is the fact that divorce and separation tends to put many women back into newpartner sexual relationships. Previous studies attribute the increased prevalence of sexually transmitted infections among older women to an increased divorce rate [23, 24]. Demographic data in Austria (Statistik Austria) report that the peak age for divorce is around 35-40 years [24] which corresponds to our finding of a second HPV peak at around this age range. The second HPV re-peak between 51 and 55 years of age may likewise be explained by an increased risk of new infections as well as by the accompanying age-related anatomical changes in the vulva and vaginal mucosa following menopause at this age. Another explanation for the HPV surge in an older age may be the hypothesis of a latent HPV infection persisting below detection limit and reactivating at some point due to declining immunity or other comorbidities commonly seen in advanced age. This hypothesis has been evidenced in some animal studies or in patients with recurrent respiratory papillomatosis [25-28].

As in several other studies, HPV 16 is clearly the most dominant genotype. It is detected in cervical samples of one out of 20 of the study population. Although HPV 18 is the second common genotype present in cervical cancer samples, it is obviously surpassed by several other genotypes among women with no known cytological abnormalities [29]. Genotypes 31 and 33 - for example - were shown to dominate cervical infection following HPV 16 both in our study and in a study from several European countries [29]. This pattern was also shown to persist among women with high-grade intraepithelial neoplasia [29]. Moreover, data from the WHO ICO information centre on HPV infection (last updated on 20th March 2015) reports that HPV 33 may be the second common genotype detected in cervical cancer samples next to HPV 16 in Austria [30]. The plausibility of this report, however, is questionable. Moreover, in our study, only one of the women with HPV 33 positive samples was diagnosed with abnormal PAP. Further epidemiological studies need to be undertaken in order to clarify or solidify this prevalence pattern among cervical cancer patients in Austria.

\section{HPV infection and lifestyle factors}

Our study showed a threefold higher risk of HPV infection among current smokers, which persisted even after 
adjusting for other behavioural factors like number of lifetime sexual partners and age at first sexual contact. This might indicate that smoking per se predisposes to HPV infection as is also shown by other studies [31-33]. Tobacco use was reported to have local and systemic immunosuppression effect increasing the probability of acquisition of an HPV infection following an exposure [33]. The exact biological mechanism, however, is not yet clear. This highlights the need to evaluate the exact role of smoking in the natural history of genital HPV infection. Contrary to smoking, high BMI was not associated with increased risk of HPV infection. The fact that HPV infection was significantly higher in non-overweight individuals in our study might be a finding by chance or it might indicate a possible association between physical appearance and sexual behaviour.

\section{HPV infection across Tyrolean districts}

Our finding of higher HPV prevalence in eastern districts of Tyrol compared to those in the west seems to parallel the regional differences in cervical cancer incidence and mortality observed by W Oberaigner et al. [16]. This association persisted even after eliminating the significant age difference between the two regions. Other confounding factors like number of life time sexual partners and age at first sexual contact were considered and adjusted for. Yet the significant difference in HPV prevalence between east and west was persistent, particularly among women above the age of 30 years. However, since questions regarding sexual behaviour may be sensitive, responders' bias and residual confounding due to these factors can still not be convincingly excluded. Other host and /or pathogen associated factors differentially predisposing to HPV infection and persistence across these geographical regions may be interesting to investigate.

\section{HPV immunization}

Surveys from several countries that have introduced free-of-charge HPV vaccination program since the approval of the vaccines have demonstrated a high vaccine coverage rate of more than $70 \%[8,34]$. Accordingly, the prevalence of hrHPV infection has reduced significantly in the years after vaccine introduction. The low immunization coverage $(3.7 \%)$ in the Austrian population may be, on one hand, a reflection of the reluctance of the country to provide the vaccine free of charge for the eligible age group coupled with the conservative view of the population towards vaccines particularly towards newly introduced vaccines. On the other hand, however, with the median age of 35 years, the majority of our study population was beyond the age of eligibility as the vaccines were introduced explaining the low coverage to some extent. Our study assessed the attitudes of the study population towards HPV vaccine. The fact that majority of the studied women showed undecidedness about getting vaccinated- which may indirectly reflect undecidedness about letting their children vaccinated - indicates the urgent demand for public health action towards raising awareness on HPV vaccine. Further surveys need to be undertaken which investigate the level of information and the possible barriers to HPV vaccine acceptance.

\section{Conclusion}

This study presents the first data on prevalence and genotype distribution of cervical HPV infections among women with no previously known cytological abnormalities in west Austria. Factors including smoking, number of life time sexual partners, age at first sexual contact and several socio-demographic factors, namely marital status and geographical region were identified as risk factors for age adjusted HPV prevalence. The finding of higher HPV prevalence in the eastern compared to the western district of the study region may - at least partly - explain the east-west gradient in the standardized incidence rate of cervical cancer in the region. The strikingly low HPV vaccine coverage may change with the recently introduced school-based vaccination program [35]. On the other hand, this data - with the extremely low vaccine coverage rate - will serve as baseline pre-vaccine information for further evaluation of the impact of the newly implemented gender-neutral HPV vaccine program in Austria.

\section{Additional files}

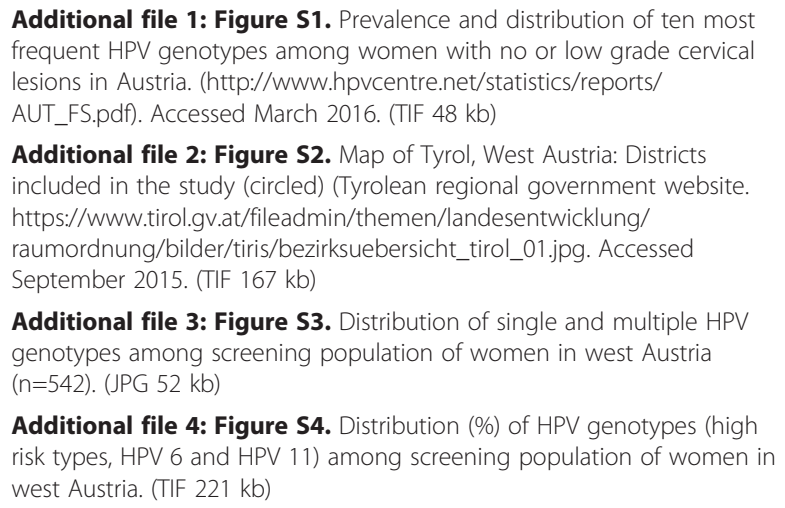

Additional file 2: Figure S2. Map of Tyrol, West Austria: Districts included in the study (circled) (Tyrolean regional government website. https://www.tirol.gv.at/fileadmin/themen/landesentwicklung/ raumordnung/bilder/tiris/bezirksuebersicht_tirol_01.jpg. Accessed September 2015. (TIF 167 kb)

Additional file 3: Figure S3. Distribution of single and multiple HPV genotypes among screening population of women in west Austria $(\mathrm{n}=542)$. (JPG $52 \mathrm{~kb})$

Additional file 4: Figure S4. Distribution (\%) of HPV genotypes (high risk types, HPV 6 and HPV 11) among screening population of women in west Austria. (TIF $221 \mathrm{~kb}$ )

\section{Acknowledgements \\ Authors thank: all medical technical assistants (MTAs) at the division of virology, Medical University of Innsbruck, for the technical assistance of HPV testing and genotyping. Authors also thank Tyrolean science fund (TWF) and MFF for the financial support.}

Funding

Tyrolean science fund (Tiroler Wissenschaftsfonds: to W.B. GZ:UNI-0404/1446) and MFF Tirol (Projektvorschlag Nr. 262). 


\section{Availability of data and materials}

For a spreadsheet of the raw data - excel or SPSS file containing information from the questionnaires and results of HPV tests - the corresponding author may be contacted (wegene.borena@i-med.ac.at).

\section{Authors' contributions}

All authors have contributed substantially to the conception, design and manuscript preparation. AW, KHK, EM, PM, JM and NR contributed to data acquisition. AG and MG assisted in HPV sequencing and data entry. CM und DVL contributed to the conception of the study and critically reviewed the manuscript. WB contributed to all stages of the work, carried out the main part of data analysis and manuscript preparation. All authors read and approved the final manuscript

\section{Competing interests}

The authors declare that they have no competing interests.

\section{Consent for publication}

Not applicable.

\section{Ethics approval and consent to participate}

This study was approved by the Ethical Committee of the Medical University of Innsbruck (Ethics committee approval number: UN 4821). Each study participant has been informed about the study and has signed consent for participation.

\section{Author details}

'Division of Virology, Medical University of Innsbruck, Schoepfstrasse 41, 6020 Innsbruck, Austria. ${ }^{2}$ Department of Gynaecology and Obstetrics, Medical University of Innsbruck, Innsbruck, Austria. ${ }^{3}$ Landeck, Austria. ${ }^{4}$ Innsbruck, Austria. ${ }^{5}$ Kufstein, Austria. ${ }^{6}$ Imst, Austria. 'Woergl, Austria.

\section{Received: 1 April 2016 Accepted: 24 August 2016}

\section{Published online: 26 August 2016}

\section{References}

1. zur Hausen H. Papillomaviruses causing cancer: evasion from host-cell control in early events in carcinogenesis. J Natl Cancer Inst. 2000;3(92(9)): 690-8.

2. Scheurer ME, Tortolero-Luna G, Adler-Storthz K. Human papillomavirus infection: biology, epidemiology, and prevention. Int J Gynecol Cancer. 2005;15(5):727-46.

3. Trottier H, Franco EL. The epidemiology of genital human papillomavirus infection. Vaccine. 2006:24 Suppl 1:S1-15.

4. Garland SM, Hernandez-Avila M, Wheeler CM, et al. Quadrivalent vaccine against human papillomavirus to prevent anogenital diseases. N Engl J Med. 2007;356(19):1928-43.

5. Joura EA, Giuliano AR, Iversen OE, Bouchard C, Mao C, Mehlsen J, Moreira Jr ED, Ngan Y, et al. Broad spectrum HPV vaccine study. A 9-valent HPV vaccine against infection and intraepithelial neoplasia in women. N Engl J Med. 2015; 372(8):711-23.

6. WHO Countries using HPV vaccine http://www.who.int/immunization/ diseases/hpv/decision_implementation/en/. Accessed 2 Feb 2015

7. Paavonen J, Naud P, Salmerón J, et al. Efficacy of human papillomavirus (HPV)-16/18 AS04-adjuvanted vaccine against cervical infection and precancer caused by oncogenic HPV types (PATRICIA): final analysis of a double-blind, randomised study in young women. Lancet. 2009;374(9686): 301-14

8. Tabrizi SN, Brotherton JM, Kaldor JM, et al. Assessment of herd immunity and cross-protection after a human papillomavirus vaccination programme in Australia: a repeat cross-sectional study. Lancet Infect Dis. 2014;14(10): 958-66. doi:10.1016/S1473-3099(14)70841-2.

9. Harrison C, Britt H, Garland S, et al. Decreased management of genital warts in young women in Australian general practice post introduction of national HPV vaccination program: results from a nationally representative cross-sectional general practice study. PLoS One. 2014;9(9), e105967.

10. Brotherton JM, Fridman M, May CL, et al. Early effect of the HPV vaccination programme on cervical abnormalities in Victoria, Australia: an ecological study. Lancet. 2011;377(9783):2085-92.

11. Bresse X, Goergen C, Prager B, et al. Universal vaccination with the quadrivalent HPV vaccine in Austria: impact on virus circulation, public health and cost-effectiveness analysis. Expert Rev Pharmacoecon Outcomes Res. 2014;14(2):269-81.

12. http://www.bmg.gv.at/home/Schwerpunkte/Gesundheitsfoerderung_ Praevention/Impfen/HPV Impfung. Accessed May 2015

13. Bachtiary B, Obermair A, Dreier B, et al. Impact of multiple HPV infection on response to treatment and survival in patients receiving radical radiotherapy for cervical cancer. Int J Cancer. 2002;102(3):237-43.

14. Birner P, Bachtiary B, Dreier B, et al. Signal-amplified colorimetric in situ hybridization for assessment of human papillomavirus infection in cervical lesions. Mod Pathol. 2001;14(7):702-9.

15. Rössler $\mathrm{L}$, Reich $\mathrm{O}$, Horvat $\mathrm{R}$, et al. Human papillomavirus in high-grade cervical lesions: Austrian data of a European multicentre study. Wien Klin Wochenschr. 2013;125(19-20):591-9.

16. Oberaigner W, Mühlböck H, Harrasser L. Tumorregister Tirol, Bericht für das Diagnosejahr 2010. Innsbruck: IET-Bericht; 2013.

17. Cirkel C, Barop C, Beyer DA. Method comparison between Munich II and III nomenclature for Pap smear samples. J Turk Ger Gynecol Assoc. 2015;16(4): 203-7.

18. World Health Organization International Agency for Research on Cancer. IARC Monographs on the Evaluationof Carcinogenic Risks to Humans, Volume 90 Human Papillomaviruses. 2007.

19. WHO HPV information center. http://www.hpvcentre.net/dataquery.php. Accessed June 2015

20. Iftner T, Eberle S, Iftner A, et al. Prevalence of low-risk and high-risk types of human papillomavirus and other risk factors for HPV infection in Germany within different age groups in women up to 30 years of age: an epidemiological observational study. J Med Virol. 2010;82(11):1928-39.

21. Dunne EF, Unger ER, Sternberg $M$, et al. Prevalence of HPV infection among females in the United States. JAMA. 2007:297(8):813-9.

22. Franceschi $S$, Rajkumar $R$, Snijders PJ, et al. Papillomavirus infection in rural women in southern India. Br J Cancer. 2005:14: 92(3):601-6.

23. Idso C. Sexually transmitted infection prevention in newly single older women: a forgotten health promotion need. Journal for Nurse Practitioners. 2009;5(6):440-6

24. http://www.statistik.at/web de/statistiken/menschen und gesellschaft/ bevoelkerung/ehescheidungen/019911.html. Accessed June 2015.

25. Gravitt PE. The known unknowns of HPV natural history. J Clin Invest. 2011. 121(12):4593-9. doi:10.1172/JCl57149. Epub 2011 Dec 1. Review.

26. Selvakumar $R$, Schmitt $A$, Iftner $T$, et al. Regression of papillomas induced by cottontail rabbit papillomavirus is associated with infiltration of CD8+ cells and persistence of viral DNA after regression. J Virol. 1997;71(7):5540-8.

27. Abramson AL, Nouri M, Mullooly V, et al. Latent Human Papillomavirus infection is comparable in the larynx and trachea. J Med Virol. 2004;72(3): 473-7.

28. Chan PK, Ho WC, Wong MC, et al. Epidemiologic risk profile of infection with different groups of human papillomaviruses. J Med Virol. 2009;81(9): 1635-44. doi:10.1002/jmv.21575.

29. Tjalma WA, Fiander A, Reich O, HERACLES/SCALE Study Group, et al. Differences in human papillomavirus type distribution in high-grade cervical intraepithelial neoplasia and invasive cervical cancer in Europe. Int J Cancer. 2013;132(4):854-67. doi:10.1002/ijc.27713.

30. WHO ICO HPV Information center http://www.hpvcentre.net/parser. php?xml=M1_Cervical cancer by histology HPV type distribution Top\&iso=AUT\&title=Module 1: HPV prevalence estimates - Invasive cervical cancer - Top 10 HPV oncogenic types (Country/Regions). Accessed Aug 2016.

31. Sarian LO, Hammes LS, Longatto-Filho A, et al. Increased risk of oncogenic human papillomavirus infections and incident high-grade cervical intraepithelial neoplasia among smokers: experience from the Latin American screening study. Sex Transm Dis. 2009:36(4):241-8.

32. Syrjänen K, Shabalova I, Petrovichev N, et al. Smoking is an independent risk factor for oncogenic human papillomavirus (HPV infections but not for high-grade CIN. Eur J Epidemiol. 2007;22(10):723-35.

33. Sopori M. Effects of cigarette smoke on the immune system. Nat Rev Immunol. 2002;2(5):372-7.

34. Kavanagh K, Pollock KG, Potts A, et al. Introduction and sustained high coverage of the HPV bivalent vaccine leads to a reduction in prevalence of HPV 16/18 and closely related HPV types. Br J Cancer. 2014;110(11):2804-11.

35. Austrian Ministry of Health. http://www.bmg.gv.at/cms/home/attachments/3/ 8/4/CH1426/CMS1389279419763/pressetext_hpv.pdf. Accessed October 2015. 